\title{
O valor probatório da assistência técnica
}

\author{
Probational value of the technical assistance
}

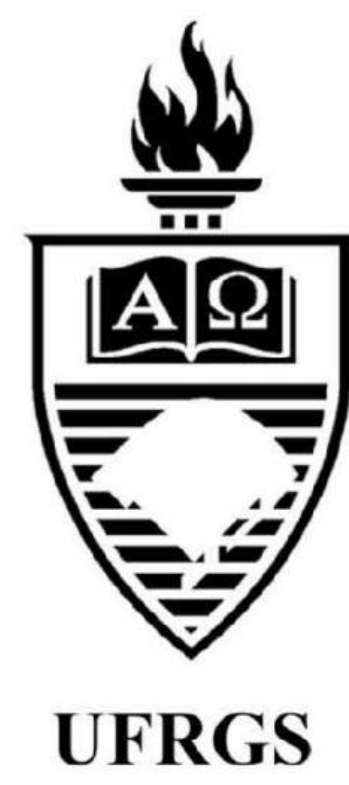

Herlon Milagres Leite

Universidade Católica de Petrópolis

Jamel Salles de Souza Leite

Universidade Católica de Petrópolis

\section{Rodrigo Grazinoli Garrido}

Universidade Federal do Rio de Janeiro e

Universidade Católica de Petrópolis 


\title{
O valor probatório da assistência técnica
}

\author{
Probational value of the technical assistance
}

Herlon Milagres Leite *

Jamel Salles de Souza Leite ${ }^{* *}$

Rodrigo Grazinoli Garrido***

\section{REFERÊNCIA}

LEITE, Herlon Milagres; DE SOUZA, Jamel Salles; GARRIDO, Rodrigo Grazinoli. O valor probatório da assistência técnica. Revista da Faculdade de Direito da UFRGS, Porto Alegre, n. 38, p. 277-289, ago. 2018.

\section{RESUMO}

Busca-se analisar o papel do assistente técnico no processo civil e penal e a natureza jurídica da prova produzida por ele. Baseando-se na documentação indireta de fontes primárias, legislação, e secundárias, julgados e doutrina, apresenta-se um quadro comparativo entre a assistência técnica e a perícia oficial no que se refere à natureza jurídica e a vinculação (de meio ou de fim) do juiz ao exame técnico. Em virtude da abundância de material, partiu-se dos padrões processuais civis para lançar luz sobre a assistência técnica penal. Conclui-se que, mormente no processo penal, certa suspeição paira sobre o parecer técnico. Contudo, não há a priori motivos para desconsiderar a característica de prova técnica do parecer técnico, no mesmo nível epistêmico do laudo pericial.

\section{PALAVRAS-CHAVE}

Perito oficial. Laudo pericial. Parecer técnico. Prova pericial.

\section{ABSTRACT}

The aim of this study is to analyze the role of technical assistant in civil and criminal proceedings and the legal nature of the proof produced by him. Based on the indirect documentation of primary, legislative, and secondary sources, judgments and doctrine, a comparative table is presented between technical assistance and official expertise as regards legal nature and linkage (means or end) judge to the technical examination. Due to the abundance of material, it was based on civil procedural standards to shed light on criminal technical assistance. It is concluded that, especially in the criminal proceedings, some suspicion hovers over technical advice. However, there is no a priori reason to disregard the technical proof characteristic of the technical opinion, at the same epistemic level as the expert report.

\section{KEYWORDS}

Official expert. Expert report. Technical opinion. Expert evidence.

\section{SUMÁRIO}

Introdução. 1. Dos Peritos. 1.1. Tipos de Peritos. 2 Assistente Técnico. 3. Natureza Jurídica da Assistência Técnica. 4. Valor Probatório do Parecer Técnico. Conclusão. Referências.

\section{INTRODUÇÃO}

O exame técnico de evidências, tanto realizado pelo expert contratado pela parte, como

\footnotetext{
* Mestrando pela Universidade Católica de Petrópolis. Especialista em Direito Constitucional pela Universidade de Brasília. Oficial de Justiça Avaliador do Tribunal de Justiça de Minas Gerais.

** Mestrando pela Universidade Católica de Petrópolis. Especialista em Direito Constitucional pela Universidade de Brasília. Oficial de Justiça Avaliador do Tribunal de Justiça de Minas Gerais.

*** Doutor em Agronomia pela Universidade Federal Rural do Rio de Janeiro. Perito Criminal da Polícia Civil do Estado do Rio de Janeiro Diretor do Instituto de Pesquisa e Perícias em Genética Forense. Professor Adjunto da Universidade Federal do Rio de Janeiro e da Universidade Católica de Petrópolis. Professor do Programa de Pós-Graduação em Direito Universidade Católica de Petrópolis.
} 
pelo perito oficial ou judicial, vem se convertendo em meio de prova essencial para o devido processo legal. Este artigo versa sobre o assistente técnico, especialista em algum assunto, contratado pela parte para auxiliá-la. Este profissional, por meio de seu parecer técnico, deve concordar, criticar ou complementar o laudo pericial emitido pelo perito, cabendo ao magistrado, pelo princípio do livre convencimento, analisar e ponderar sobre os argumentos, podendo, inclusive, basear sua decisão no parecer.

Dessa forma, objetiva-se verificar se a natureza jurídica do parecer técnico é a mesma do laudo pericial; e de forma mais específica, destacar alguns pontos considerados importantes sobre o assistente técnico e o perito oficial ou judicial. A análise parte do que já se encontra bem precipitado no processo civil, para alcançar um possível entendimento para o processo penal. Além disso, buscou-se determinar a possível vinculação, de meio ou de fim, do magistrado ao exame técnico reatado no laudo pericial e parecer técnico, tudo com base em entendimentos teóricos e interpretações jurisprudenciais.

\section{DOS PERITOS}

Peritos são especialistas capazes de prestar esclarecimentos às autoridades em sua área de conhecimento. Assim, o perito é pessoa com conhecimento técnico, habilitada ou entendida em uma ciência ou arte; é o profissional com qualificação em certa área; é louvado ou experto em determinada matéria que, graças a seus conhecimentos, atua como fonte de consulta na resolução de uma demanda judicial.

O termo "perito" deriva do latim peritus, formado a partir do verbo perior, que quer dizer experimentar, conhecer por experiência. É o sujeito ativo da perícia. Trata-se de uma pessoa que, pelas qualidades especiais que possui, normalmente de natureza científica ou artística, "supre as insuficiências do juiz no que tange à verificação, ou apreciação daqueles fatos da causa que para tal exijam conhecimentos especiais ou técnicos" (LEHNEN, 2001, p. 06).

Conforme Walter José Ferreira (2011, p. 14), o perito, no exercício de sua função, tem o dever de levar em conta "os efeitos em benefício da sociedade, propiciando bem-estar a todos que têm interesse no deslinde da controvérsia". Prossegue o autor, explicando que "as características de excelência moral, intelectual e técnica são condições essenciais para o encargo a ser confiado pelo juízo".

A perícia deve ser realizada por um profissional, que, para todos os efeitos, é considerado auxiliar da justiça e, por isso, submete-se às mesmas causas de suspeição dos juízes. Não cabe ao perito acusar, defender, julgar ou decidir. Sua função é verificar, observar e relatar a realidade dos fatos. O perito atua no sentido de examinar e certificar pela apreciação ou interpretação dos fatos e, depois, transmitir um parecer denominado laudo pericial.

É possível considerar que o perito, a despeito de sua formação específica, é na sua generalidade, um profissional da ciência forense. Esta ciência pode ser entendida como a aplicação do conhecimento de diversas ciências e artes à matéria ou a problemas legais. Apesar de se basear em outros saberes, a ciência forense apresenta objetivos próprios e muitas das técnicas desenvolvidas nos últimos anos foram direcionadas especificamente para fins forenses, permitindo o reconhecimento de uma ciência forense em si. Além disso, a ciência forense não se restringe às análises química, físicas $\mathrm{e}$ biológicas, mas guarda especial atenção à coleta, preservação e interpretação das evidências (SIEGEL e SAUKKO, 2013)

Assim, diversos profissionais, ao voltarem as atividades aos problemas legais, são peritos em potencial no ramo do conhecimento que dominam. Assim, um médico se converte em 
perito quando é requisitado pelo juiz para informar sobre um fato relacionado com as atividades privativas de médico ou quando é nomeado no cargo de perito oficial. Da mesma maneira um arquiteto, um mecânico, um economista, um contador e assim por diante.

\subsection{Tipos de Peritos}

O perito pode ser judicial, oficial de natureza criminal e ad hoc. O perito judicial é o especialista técnico indicado pelo juiz, que atua especialmente em causas cíveis, emitindo sua opinião sobre questões que lhe são submetidas pelas partes ou pelo juiz, para esclarecer fatos que ajudem o magistrado a formar sua convicção. $\mathrm{O}$ perito judicial deve ser um técnico especialista no assunto que precisa de esclarecimentos.

De acordo com o parágrafo $1^{\circ}$, do artigo 156, do NCPC “o juiz será assistido por perito quando a prova do fato depender de conhecimento técnico ou científico". Esse será nomeado entre "profissionais legalmente habilitados e os órgãos técnicos ou científicos devidamente inscritos em cadastro mantido pelo tribunal ao qual o juiz está vinculado". Claramente, a nomeação judicial de um perito pode também ser realizada no Processo Penal, especialmente em exames por precatória e quando houver discrepância entre as conclusões previamente apresentadas por outros peritos (CPP art. 177 e 180).

Então, o perito judicial é a pessoa escolhida pelo juiz em razão de seus conhecimentos técnicos, que tem por missão proceder a análise, as verificações e as apreciações de fato, a partir das quais, consigna o resultado em um relatório. Realiza, portanto, uma diligência processual, na forma de exame técnico do material, dos fatos, das coisas e pessoas relacionadas à questão judicializada.

O perito é normativamente regido, em geral, pela Constituição Federal de 1988, embora não de forma textual; pelos artigos 156 a 157, do
Código de Processo Civil de 2015; pelos artigos 275 a 281, do Código de Processo Penal de 1941; e pela Lei $\mathrm{n}^{\circ} 12.030$, de 17 de setembro de 2009, que dispõe sobre as perícias oficiais de natureza criminal. Além desses textos normativos, existem muitas outras leis, provimentos, resoluções, normas de diversas profissões que, em alguma medida, definem perito.

$$
\text { No âmbito processual penal, }
$$

independentemente da nomeação judicial, o perito oficial, ao seu turno, é aquele provido no cargo por ato executivo, na forma da lei. Normalmente o perito oficial é a pessoa que exerce a atividade por profissão e pertence a órgão especial do Estado, destinado exclusivamente a produzir perícias, "assegurado autonomia técnica, científica e funcional” (Lei 12030/2009). Para ser perito oficial o especialista precisa ser servidor público concursado e empossado no cargo, atuando preferencialmente em causas criminais, por isso é também denominado de perito oficial de natureza criminal.

Quanto à nomeação dos peritos na justiça penal, o artigo 159 do Código de Processo Penal determina que o exame de corpo de delito e outras perícias serão realizados por um perito oficial, portador de diploma de curso superior e, de preferência, que tenha habilitação técnica relacionada à natureza do assunto a ser analisado. Ressalta-se que, há obrigatoriedade de atuação dos peritos oficiais de natureza criminal sempre que houver vestígios materiais relacionados ao fato investigado ou julgado.

Observando a legislação específica, a Lei $\mathrm{n}^{\mathrm{o}} 12.030$ de 2009 define como peritos de natureza criminal: "os peritos criminais, os peritos médico legistas e os peritos odontolegistas com formação superior específica detalhada em regulamento, de acordo com a necessidade de cada órgão e por área de atuação profissional" (art $5^{\circ}$ da Lei $n^{\circ}$ 12.030/2009).

Nesse ponto, vale lembrar que mesmo no processo civil, quando se tratar de perícia que 
busque comprovar autenticidade ou a falsidade de documento ou de interesse médico-legal, o artigo 478 do NCPC estabelece que o perito do juízo deva ser escolhido preferencialmente entre "os técnicos dos estabelecimentos oficiais especializados".

Já o perito ad hoc, perito para caso específico ou perito não oficial é aquele designado pela autoridade, costumeiramente, policial para apenas uma ocasião. Vale dizer, que os nomeados transitoriamente para peritos devem prestar o compromisso de esclarecer certo assunto. Na forma dos parágrafos $1^{\circ}$ e $2^{\circ}$, do artigo 159 do Código de Processo Penal, "na falta de perito oficial, o exame será realizado por duas pessoas idôneas, portadoras de diploma de curso superior preferencialmente na área específica, dentre as que tiverem habilitação técnica relacionada com a natureza do exame".

\section{DOS ASSISTENTES TÉCNICOS}

Por outro lado, o assistente técnico é o profissional da ciência forense contratado por uma das partes envolvidas em processo judicial ou administrativo para analisar o laudo pericial, acompanhar a realização de exames periciais, ou mesmo, realizar novos exames. No caso de perícias complexas, quando há indicação de mais de um perito, a parte também poderá indicar mais de um assistente técnico.

Assim, o profissional contratado é um auxiliar da parte e não do juízo. Como auxiliar da parte, o assistente técnico não precisa prestar compromisso de bem e fielmente prestar o serviço. $\mathrm{O}$ assistente técnico, depois de analisar o laudo pericial ou acompanhar a perícia e, ainda, eventualmente, realizar seus próprios exames, tem que emitir seu parecer técnico, onde registra seu juízo técnico-científico, que pode ser ou não no sentido do laudo pericial, elaborando as críticas, raciocínios e as diversas conclusões alcançadas.
A contratação do assistente técnico é de iniciativa da parte e indicá-lo é facultativo. A despeito de não haver obrigatoriedade legal em se constituir um assessor técnico importante, quando contratado previamente e participar dos trabalhos desde o início, acompanhando todo o processo, inclusive na elaboração dos quesitos apresentados aos peritos, o assistente fará parte do processo judicial (FERREIRA, 2011, p. 72).

Portanto, o assistente técnico deverá ser cauteloso no que diz ao contrato de prestação de serviços, estipulando cláusulas claras e definidas por etapas na realização do trabalho, por exemplo: na petição inicial, na elaboração de quesitos, em exames de contraprovas (FERREIRA, 2011, p. 72).

Apesar da figura do assistente técnico acompanhar há anos o processo civil, estando, atualmente, estabelecida nos termos do parágrafo $1^{\circ}$ do artigo 465 do NCPC, no processo penal, a positivação do assistente técnico foi dada apenas em 2008, por meio de modificação do artigo 159 do CPP trazida pela Lei 11.690. A partir de então, tornou-se facultativo às partes, Ministério Público; assistente de acusação: ofendido; querelante e acusado, a indicação de assistente técnico. Com isso, o Ministério Público do Estado do Rio de Janeiro, p.ex., reestruturou em 2011 o Grupo de Apoio Técnico Especializado - GATE, que entre outros objetivos, passou a ser responsável por emitir pareceres e outros elementos de informação e convencimento (Resolução GPGL n. 1695/2011).

No sistema vigente, em princípio, perito e assistentes técnicos trabalharão independentemente no processo penal. Face às demandas da Lei 11.690/2008, o assistente atuará após "sua admissão pelo juiz e após a conclusão dos exames e elaboração do laudo pelos peritos oficiais" (art. $159 \S^{\circ}$ do CPP). Além disso, os exames assistenciais ocorrerão no ambiente do órgão oficial, sob os olhos do perito. Já no processo civil, em geral, não há qualquer 
impedimento do trabalho em conjunto, e têm prazos separados para entrega de suas conclusões.

No entanto, com a garantia do contraditório, atuando a defesa técnica em fase investigatória, especialmente na investigação criminal defensiva ${ }^{2}$, no inquérito policial e nas CPIs, torna-se difícil afastar o mesmo entendimento para a produção da prova técnica. Assim, apesar de não ser o posicionamento majoritário, para Vaz e Galvão (2011) a lei não proibiu a assistência técnica extrajudicial, mas, apenas, veio regulamentar o contraditório diferido, pois, na maioria das vezes, a prova técnica penal já fora produzida tão $\operatorname{logo}$ a autoridade policial tomou conhecimento dos fatos que deixaram vestígios.

Esse posicionamento já era considerado pelo STF em 2007, anteriormente à lei 11.690/2008. Ao relatar o HC 92.599-BA, o Ministro Gilmar Mendes, deferiu a juntada de parecer de assistente técnico, erroneamente chamado de laudo pericial, em inquérito policial: "Destarte, nos termos da jurisprudência colacionada, entendo não haver razão jurídica plausível para que a Corte Especial do STJ indefira pedido de juntada do laudo pericial requerida pela defesa do ora paciente".

Em suma, assistência técnica é função desempenhada por um profissional especializado em determinada área do conhecimento pertinente a exames periciais realizados ou realizáveis em um processo judicial de natureza criminal ou civil. Esse profissional emite parecer técnico que tem por escopo fortalecer com dados técnicos os argumentos das partes. Assim, a principal característica dos assistentes técnicos é a confiança das partes. Ademais, não estão sujeitos a impedimento ou suspeição. Com isso, a dúvida que se levanta e que interessa para este estudo é

\footnotetext{
${ }^{2}$ Modelo de investigação protagonizada pela vítima ou seu representante legal, buscando garantir o contraditório e a paridade de armas por meio da identificação de fontes de prova e realização ou requisição de diligências para produzi-las. Esse modelo já é adotado em alguns países,
}

saber se o parecer técnico extrajudicial pode ser considerado prova pericial elucidativa que auxilia na decisão do juiz.

\section{NATUREZA JURÍDICA DA ASSISTÊNCIA TÉCNICA}

A função dos assistentes técnicos é de extremada importância na identificação e na fiscalização dos dados notados pelo perito no momento do exame pericial, com a finalidade de, posteriormente, indicar em seus pareceres, possíveis equívocos, falhas ou omissões no laudo pericial que possam vir a modificar ou mesmo proscrever a conclusão. Tem sido cada vez mais comum, durante a atuação dos assistentes, sobretudo em perícias de laboratório, p.ex., verificações de lotes e validades de reagentes, análise dos certificados de calibração de equipamentos, além dos demais certificados dos sistemas de gestão da qualidade, incluindo a especialização dos peritos e a garantia da cadeia de custódia das evidências (GARRIDO e ARAUJO, 2014)

Na vigência do Código de Processo Civil de 1939, a perícia era realizada por perito escolhido pelo juiz e as partes podiam indicar assistente técnico para acompanhar a perícia, podendo impugnar as conclusões do perito judicial. O Código de Processo Civil de 1973 em sua versão original, também atribuía grande importância ao assistente técnico indicado pela parte, exigindo que atuasse com total isenção, sem tolerar qualquer relação de amizade ou de trabalho entre o assistente técnico e uma das partes, sob pena afastamento do consultor técnico (LAZARI; et alli, 2007, p. 01).

A despeito de, atualmente, não se ter mais positivada essas suspeições, ainda se espera

como a Itália e EEUU. No Brasil, as propostas sobre o tema estão contempladas no Projeto de Lei do Novo Código de Processo Penal (art. 13 do PL 8045/10), e, de forma tímida, na Lei n. 13.245/2016 (ZINARDI, 2016). 
que o assistente técnico seja imparcial e de diga a verdade, no que se equipararia aos peritos judiciais. Contudo, essa equiparação teórica nem sempre é realizada, pois se reconhece que sendo o assistente, perito da parte, é de se supor que favorece a quem o contratou. Seria, no mínimo, ilógico, que a parte juntasse prova técnica facultativa que a prejudicasse.

Com a nova redação dada ao artigo 138 à Lei no 8.455 de 24 de agosto de 1992, a arguição de parcialidade só pode ser admitida com relação ao perito judicial, isentando os assistentes técnicos das partes. Verifica, destarte, que com o passar do tempo os assistentes técnicos assumiram mais o papel de consultores das partes do que de assistentes periciais, devido à isenção de responsabilidade concebida pela nova redação do artigo 138 do Código de Processo Civil de 1973. O NCPC de 2015 segue a mesma linha, abrindo mão da exigência da imparcialidade dos assistentes técnicos, tratando-os como auxiliar das partes.

Nas explicações de Carlos Alberto Carmona (1996, p. 537), não significa que a nova lei entenda que os pareceres dos assistentes técnicos são inidôneos ou viciados, apenas reconheceu que os assistentes técnicos das partes "se esforçavam para trazer elementos válidos e reais, que poderiam esclarecer os fatos, mas que realçassem os elementos técnicos mais favoráveis para a parte assistida”. Diante desse fato, decorrente da natureza da relação entre $o$ assistente técnico e a parte, que o contrata e paga pelos seus serviços, era preciso punir abuso.

Qualquer ato culposo ou doloso do assistente técnico em prejuízo das partes é tratado como crime praticado por particular. Sendo certo que não seria possível enquadrar o assistente técnico no tipo penal de falsa perícia, o qual só pode ser praticado por quem realiza a perícia - o perito. Por isso, a parte precisa ter muito cuidado quando contratar um assistente técnico para auxiliá-la no processo, especialmente no que diz respeito aos conhecimentos técnicos necessários à realização de parecer sobre o laudo pericial elaborado pelo perito oficial ou judicial.

$\mathrm{O}$ assistente técnico não tem a simples função de elaborar parecer técnico independente, divergente ou crítico do laudo pericial. Seu maior papel no processo é diligenciar a realização da perícia para evidenciar com o perito judicial ou frente ao já evidenciado pelo perito oficial de natureza criminal os aspectos que são de interesse à elucidação dos fatos, em duplo aspecto: numa visão geral e numa visão mais específica voltada à parte que o contratou.

Em matéria criminal, por meio da Lei $n^{\circ}$ 11.690, de 09 de junho de 2008, o legislador reformista do Código de Processo Penal, inspirado no Direito Processual Civil ampliou o poder de contestação das partes em relação à prova pericial, por meio da criação do assistente técnico criminal. Esses assistentes técnicos poderão apresentar pareceres em prazo a ser fixado pelo juiz ou ser inquiridos em audiência.

Sendo de interesse das partes, poderão requerer o material probatório que serviu de base à perícia para ser examinado pelo assistente técnico. Esta será realizada "no ambiente do órgão oficial, que manterá sempre sua guarda, e na presença de perito oficial, [...], salvo se for impossível a sua conservação.” (art. 159, §6 $\mathrm{CPP}$ ). Além disso, quando a perícia for complexa e abranger diversas área de conhecimento especializado, a parte poderá indicar mais de um assistente técnico (art. 159, $\S 7^{\circ} \mathrm{CPP}$ ).

\section{VALOR PROBATÓRIO DO PARECER TÉCNICO}

Não há dúvida quanto ao papel do parecer técnico extrajudicial ou judicial como auxiliar na decisão do magistrado. Contudo, tendo sido produzidos por profissionais contratados pelas partes, poder-se-ia levantar certa suspeição sobre sua parcialidade. Assim, este relatório do 
exame técnico poderia ser tratado como informe, não se lhe atribuindo o caráter de prova pericial. Nessa trilha, foi o o entendimento do Tribunal de Justiça de São Paulo, quando entendeu que a "prova unilateral, como parecer técnico, não é suficiente para concessão da liminar perseguida" (TJSP, Processo $n^{\circ} 4616962620108260000$ SP, 2011).

Também para o tribunal Regional Federal da $2^{\text {a }}$ Região, "em caso de divergência entre o laudo pericial e o parecer técnico do assistente de uma das partes, como no caso concreto, deve prevalecer, em regra, a conclusão daquele entendimento consolidado no âmbito da jurisprudência" (TRF2 ${ }^{\mathrm{a}}$, AC $\mathrm{n}^{\mathrm{o}} 331500$ RJ 1993.51.02.080207-1, 2008).

Nesse sentido, o TJMA também se manifestou de forma semelhante:

Ementa: Agravo de instrumento. Ação ordinária de resolução de contrato locatício c/c depósito das chaves e indenização por danos morais. Pedido de antecipação de tutela. Desabamento de telhado. Laudo técnico produzido unilateralmente pelo autor. Ausência da prova inequívoca da verossimilhança das alegações (artigo 273 do Código de Processo Civil). I Laudo técnico produzido unilateralmente pelo autor da ação, ora agravado, que não passou, portanto, pelo crivo do contraditório, carece de força probante necessária para configurar o pressuposto "prova inequívoca" apto a lastrear a decisão de antecipação de tutela recorrida. II Recurso conhecido e provido. Unânime (TJMA, AI no 118592006 MA, 2007).

Outra decisão que segue esse caminho foi emitida pelo Tribunal Regional Federal da $4^{\mathrm{a}}$ Região:

Ementa: Acidente de trânsito. Omissão. Ausência de conservação de rodovia. Responsabilidade civil subjetiva. Nexo causal não comprovado. Laudo produzido unilateralmente sem observância do contraditório. Força probatória mitigada. Honorários advocatícios. Minoração. Descabimento. [...]. 3.- O laudo pericial produzido unilateralmente pela parte, embora seja um elemento de convicção, foi produzido sem a observância do contraditório, de modo que apresenta força probatória mitigada, no máximo podendo auxiliar no esclarecimento dos fatos, mas não pode ser a figura central de convencimento [...]. (TRF4 ${ }^{\mathrm{a}} \mathrm{R}, \mathrm{AC} \mathrm{n}^{\mathrm{o}}$ 138865920064047000 PR, 2011).

Assim, parece prevalecer na jurisprudência, mas também na doutrina, o entendimento de que o acatamento pelo juiz de parecer técnico unilateral produzido pela defesa ou pelo Parquet público afronta o princípio do contraditório, na medida em que produz prova sem a participação da parte contrária. Senão, vejamos o ensinamento de Badaró (2003) ao reconhecer que no campo probatório penal a atividade do Ministério Público realizada sem a participação do acusado é parcial e, assim, “deve ser considerado apenas como uma 'atividade de parte"'(BADARÓ, 2003, p. 222).

Por outro lado, há quem defenda a natureza de prova pericial dos pareceres técnicos, conforme jurisprudência descrita a seguir. Por exemplo, cotejando algumas decisões jurisprudenciais sobre o assunto, Marco Antonio Amaral Pires (2005, p. 99) verifica e interpreta que, no Processo Civil, é possível considerar o parecer técnico unilateral, elaborado pelo assistente técnico contratado pela parte, como prova. Tanto é que o artigo 472 do NCPC deixa claro que "O juiz poderá dispensar prova pericial quando as partes, na inicial e na contestação, apresentarem, sobre as questões de fato, pareceres técnicos ou documentos elucidativos que considerar suficientes". Contudo, para ser usado como prova pericial, a jurisprudência apresentada aponta que o parecer técnico tem que representar a mesma posição indicadas pelo conjunto probatório trazido ao processo.

De fato, o próprio laudo pericial, embora possa servir de fundamento único à procedência ou não do pedido de ação, "deve ser analisada em conjunto com as demais provas que instruem o feito" (TJMG, AC n ${ }^{\circ}$ 1.0024.03.885292-7/001, 2007). De toda forma que "O juiz apreciará a prova pericial $[. .$.$] independentemente do sujeito$ 
que a tiver promovido [...], indicando na sentença os motivos que o levaram a considerar ou a deixar de considerar as conclusões do laudo, levando em conta o método utilizado pelo perito" (Arts. $371 \mathrm{e}$ 479 NCPC).

No processo penal, por primeiro, destaca-se que antes da Lei $\mathrm{n}^{\circ} 11.690$, de 09 de junho de 2008, que alterou diversos artigos do Código de Processo Penal, inclusive os artigos 158 a 184, que disciplinam o exame do corpo de delito e das perícias em geral, só eram admitidas as perícias criminais oficiais, não existindo a figura do perito particular ou do assistente técnico (TRF $1^{\mathrm{a}} \mathrm{R}, \mathrm{RCCR} 84597$ MG, 2002, p. 121).

Com o advento da Lei $\mathrm{n}^{\circ} 11.690$, o parecer do assistente técnico criminal passou a ser aceito e considerado. Para que o assistente técnico possa realizar suas análises periciais e emitir seu parecer, terá acesso ao material usado para a realização do laudo pericial. Assim, a despeito de alguns autores (GARRIDO e SANTORO, 2016) apontarem deficiências na efetivação do contraditório proporcionado pela assistência técnica, não há o que se falar quanto ao papel da Lei 11.690 em suscitar tal possibilidade técnica no processo penal.

Com seu ingresso no processo penal, o assistente técnico poderá acompanhar todos os trabalhos realizados pelos peritos, com o objetivo de contradizer ou acrescentar em seu parecer técnico algo que considerar importante, sempre priorizando os interesses da parte que o solicitou.

A questão que surge agora é saber definitivamente se o laudo do perito e o parecer do assistente técnico têm o mesmo peso probatório em questão criminal. Claro é que com a implantação do assistente técnico no processo penal, ao garantir em certo grau o contraditório, o legislador muniu o julgador de instrumentos que o permitam confrontar as conclusões do perito oficial. Assim, podendo, inclusive, optar pelo parecer técnico ao invés do laudo pericial, uma vez que "o juiz não fícará adstrito ao laudo, podendo aceitá-lo ou rejeitá-lo, no todo ou em parte" (art. 182 do CPP) pois, estranho é o julgamento em que o magistrado, desconhecedor de um determinado mister técnico descrito em laudo ou parecer técnico, simplesmente desconsiderar ambos os relatórios (PUERARI, PORTES e GARRIDO, 2014)

Santoro e Garrido (2016) ao discutirem eventuais diferenças entre o laudo pericial e o parecer técnico, não encontraram distinção ontológica entre os dois trabalhos, que produzem informações técnicas valoráveis pelo julgador. No que concerne a deontologia, desconsideram qualquer previsão de que o perito tenha maior idoneidade, credibilidade que o assistente, a despeito de ter sido contratado pela parte. Este último deve atuar sempre com rigor científico. Assim, concluem que, desde que, o laudo pericial e o parecer técnico sejam coerentes e com razoabilidade de opinião e observância da boa ciência com comprovações estatisticamente relevantes, ambos devem servir igualmente para a auxiliar na cognição do juiz.

Da interpretação do artigo 155 do CPP, extrai-se que não existe uma hierarquia de valoração de provas, na medida em que o juiz formará sua convicção pela livre apreciação da prova produzida em contraditório judicial, não podendo fundamentar sua decisão exclusivamente nos elementos informativos colhidos na investigação, ressalvadas as provas cautelares, não repetíveis e antecipadas.

É a partir da livre e racional apreciação das provas, que o magistrado formará sua convicção, com base em preceitos de lealdade e honestidade. A despeito de, no Brasil, não haver standard probatório propriamente dito na legislação ou de forma clara na jurisprudência, é possível estabelecer valores cognitivos para as provas, a partir de padrões estrangeiros, como os norte-americanos de considerar que aprova esteja além de qualquer dúvida razoável; de que a prova seja clara e convincente; e que haja simetria das 
provas apresentadas pelas partes no processo civil (DE SOUZA, 2017). De forma geral, deve-se considerar como requisitos mínimos para a motivação do juiz adotados no Brasil: a ausência de motivos; contradições entre motivos; motivos hipotéticos; falta de enfrentamento de uma questão e a distinção entre graus de exigência da prova no processo civil e penal (BALTAZAR JÚNIOR, 2008).

Inegavelmente, a informação técnicocientífica trazida nos laudos periciais e pareceres assistenciais facilita em grande medida a cognição dos juízes. Contudo, a prova técnica tem que ser examinada em conformidade com as circunstâncias e conjunturas descritas nos autos processuais e, quando aceita pelo juiz, sua sentença deve justificar com clareza os motivos de seu acolhimento.

Dessa forma, o parecer emitido pelo assistente técnico em matéria penal, assim como no processo civil, se situa no mesmo patamar que o laudo pericial elaborado pelo perito oficial e judicial. No entanto, ainda é forte a suspeição que paira no meio jurídico, no sentido de priorizar o laudo pericial, não pelos achados técnicos, mas por dúvida quanto a parcialidade ou mesmo inveridicidade do parecer.

No âmbito penal, a despeito da jurisprudência reconhecer a improcedência da alegação de nulidade do processo pela falta do exame de corpo de delito, desde que exista outros elementos de prova (BRASIL, 2005), a obrigatoriedade legal do exame de corpo de delito, sempre que a infração deixar vestígios (CPP art. 167), estabelece uma vinculação de meio entre o juiz e o laudo pericial. Diferentemente, o parecer técnico, por seu caráter facultativo, não é capaz de gerar tal vínculo. De toda forma, a vinculação de fim, de resultado, não existe nem com o laudo pericial, nem com o parecer técnico em nenhuma das vertentes processuais.
Assim, a valorização do trabalho do assistente técnico vem se tornando essencial ao processo, como já é a do perito oficial ou judicial. De tal forma, que já surgem vozes que demandam, em nome da isonomia, o oferecimento do "assistente técnico público" àqueles que não têm condições de contratar esse profissional e fazer valer o contraditório técnico (PARISE e ARTEIRO, 2009)

\section{CONCLUSÃO}

Mesmo que pareça, irreconciliável, o papel do assistente técnico, deve ser de conjugar as posições da defesa, que o contra, com a realidade dos fatos, ou, ao menos, de apontar falhas na proposta descrita pelos peritos oficiais e judiciais. É claro que para isso, devem sustentarse na ética e na boa ciência.

No processo civil, já está bem definido que, independentemente de quem estiver produzido a prova técnica (perito ou assistente técnico), o juiz pode considera-la. Contudo, no processo penal, talvez pela recenticidade da positivação da assistência técnica, ou pelo valor do bem jurídico tutelado, percebe-se ainda muita desconfiança quanto ao parecer técnico, sendo, mesmo que não objetivamente, suscitada a suspeição dessa prova.

A despeito desta falta de confiança, não se vê, a priori, motivos para desconsiderar a característica de prova técnica do parecer técnico, no mesmo nível epistêmico do laudo pericial. Claro é que, não se pode olvidar, todavia, que o juiz não está adstrito nem mesmo ao laudo pericial à formação de seu convencimento, podendo, inclusive, decidir contra o laudo pericial, desde que embasado em outros tipos de prova e justificando sua decisão.

A contrário sensu, mesmo em uma demanda civil, o parecer técnico unilateral como única peça técnica presente no processo não pode ser considerado como prova judicial, por não 
atender ao princípio do contraditório. Certamente, com o advento da investigação criminal defensiva, irão surgir no âmbito penal cada vez mais pareceres técnicos que versem sobre exames em evidências que não alcançaram os peritos oficiais.

Todavia, este procedimento não ocorreria na persecução de origem estatal, uma vez que o exame pericial oficial deve ser realizado tão logo tenham conhecimento da infração que deixou vestígios. Assim, em face desta demanda do processo penal, parece criar uma vinculação de meio entre o juiz e o laudo pericial, diferentemente da relação que o julgador teria com o parecer técnico, mantendo a inexistência de vinculação de fim com ambas as peças técnicas.

\section{REFERÊNCIAS}

BADARÓ, Gustavo. Ônus da Prova no Processo Penal. São Paulo: RT, 2003.

BALTAZAR JUNIOR, José Paulo. Standards Probatórios no Processo Penal. Revista Jurídica, Porto Alegre, v. 363, p. 127-144, 2008.

BRASIL, Supremo Tribunal Federal, HABEAS CORPUS no 85.744-2/RJ, $2^{\mathrm{a}}$. Turma, Relator: Ministro Gilmar Mendes, julgamento em 02/08/2005. Disponível em: <www.stf.gov.br>. Acesso em: 10 ago. 2014.

CARMONA, Carlos Alberto. A prova pericial e a recente alteração do Código de Processo Civil. In: TEIXEIRA, Sálvio de Figueiredo (coord). Reforma do Código de Processo Civil. São Paulo: Saraiva, 1996. p. 537-550.

De SOUZA, Luís Felipe Pires. O Standard de Prova no Processo Civil e no Processo Penal. 19 p., 2017. Disponível em: <http://www.trl.mj.pt/PDF/O\%20standard\%20de\%20prova\%202017.pdf>. Acesso em: 21 dez. 2017.

FERREIRA, Walter José. Curso de perícia veterinária. Curso Online: Ebook, 2011.

GARRIDO, Rodrigo Grazinoli; ARAUJO, Katia. Sistemas de Gestão da Qualidade em Laboratórios de Genética Forense. Revista Espacios, vol. 35, $\mathrm{n}^{\mathrm{o}}$ 5, 2014. Disponível em: <www.revistaespacios.com/a14v35n05/14350403.html>. Acesso em: 30 set. 2017.

GARRIDO, Rodrigo Grazinoli; SANTORO, Antonio Eduardo Ramires. A natureza jurídica da manifestação dos assistentes técnicos na prova pericial no processo penal brasileiro. In: GARRIDO, Rodrigo Grazinoli; ASENSI, Felipe; Pereira, THIAGO RODRIGUES (Org.). Conflitos e Verdade no Direito. 1ed.Rio de Janeiro: Multifoco, 2016, p. 73-92

LAZARI, André Couto; et alli. Comentários aos artigos 420 a 439 do Código de Processo Civil: da prova pericial. Artigo publicado em 24 de novembro de 2007. Disponível em: <http://www.tex.pro.br/home/artigos/71-artigos-nov-2007/5732-comentarios-aos-arts-420-a-439-docpc>. Acesso em: 14 set. 2015.

LEHNEN, Fernando. Estudo jurídico-contábil da prova pericial. São Paulo: LTr, 2001.

PIRES, Marco Antonio Amaral. O papel do laudo pericial contábil na decisão judicial. Salvador, BA: Fundação Visconde de Cairu, 2005. 
PARISE, Ricardo Faiad e ARTEIRO, Rodrigo Lemos. Prova Pericial na Persecução Penal e o Princípio do Contraditório. Revista Intertemas, V5 (ETIC), n. 5, p. 1-26, 2009.

PUERARI, Daniel Navarro; PORTES, Marco Antônio de Araujo; GARRIDO, Rodrigo Grazinoli. Autonomia da prova técnica no processo. Colloquium Humanarum. vol. 11, n. Especial, p. 459-464, 2014.

SIEGEL, Jay A.; SAUKKO, Pekka J. (Eds.) Introduction. Encyclopedia of Forensic Sciences (2nd ed). Elsevier, 2013.

VAZ, Denise Provasi; GALVÃO, Danyelle da Silva. Da atuação do assistente técnico no processo penal brasileiro. RBCCrim. v. 19, n. 90, p. 211-242, 2011.

ZINARDI, Tatiane Imai. Investigação criminal defensiva: uma prática a ser difundida. Revista Justiça e Sistema Criminal, v. 8, n. 14, p. 191-216, 2016.

Recebido em: 23/10/2017

Aceito em: 23/12/2017 
